\title{
Sistemas de Alimentação Pós-Desmama de Bezerras de Corte para Acasalamento com 14/15 Meses de Idade
}

\author{
Marta Gomes da Rocha1, José Fernando Piva Lobato ${ }^{2}$
}

\begin{abstract}
RESUMO - Este trabalho foi conduzido com o objetivo de avaliar o desempenho de bezerras de corte submetidas a sistemas alternativos de alimentação, no primeiro período outono/inverno pós-desmama, por 88 dias, e, após este período, mantidas sobre pastagem melhorada, até o final do seu primeiro acasalamento, com 14-15 meses de idade. Os sistemas utilizados foram: pastagem-pastejo contínuo em pastagem cultivada de azevém (Lolium multiflorum Lam); suplementação- pastejo contínuo em pastagem natural e suplementação energético-protéica; confinamento- confinamento, a céu aberto, com silagem de sorgo + nitrogênio não-protéico (NNP). Após esse período, as bezerras pastejaram em conjunto pastagens naturais melhoradas compostas por azevém, trevo branco (Trifolium repens) e cornichão (Lotus corniculatus). Os dados foram coletados em uma Empresa Agropecuária, localizada em Dom Pedrito, RS, em 395 bezerras de corte pertencentes a três grupos genéticos: Hereford; 3/4 Hereford-1/4 Nelore; 5/8 Hereford-3/8 Nelore. Foram tomados registros de peso vivo (PV), ganho de peso médio diário (GMD) e condição corporal (CC). As bezerras mostraram comportamento semelhante quanto ao PV e GMD. A CC foi maior nos animais do grupo confinamento. No início e final da estação de acasalamento, novilhas alimentadas exclusivamente em pastagens tiveram maior PV e CC do que novilhas dos grupos suplementação e confinamento, que não diferiram entre si.
\end{abstract}

Palavras-chave: pastagens melhoradas, silagem de sorgo, suplementação

\section{Post Weaning Feeding Systems for Beef Heifers to be Bred at 14/15 Months of Age}

\begin{abstract}
The experiment evaluated the performance of beef heifers submitted to three alternatives of autumn-winter feeding systems, during 88 days, and after this period on improved pastures all together until the end of theirs first mating season, with 14-15 months of age. The systems were: Pasture- continuous grazing on cultivated annual ryegrass (L. multiflorum Lam); supplementationcontinuous grazing on natural pasture plus energy and protein supplementation; feedlot - feedlot, with sorghum silage plus non- proteic nitrogen (NNP). After this period, all heifers grazed together on improved natural pastures with annual ryegrass, white clover (Trifolium repens) and birdsfoot trefoil (Lotus corniculatus). These data were collected in a farm located in Dom Pedrito, RS, from 395 beef heifers from three genetic groups: Hereford; 3/4 Hereford -1/4 Nellore; 5/8 Hereford-3/8 Nellore. Live weight (LW), body conditions score (BCS) and live weight daily gains (LDG) were recorded. No differences could be detected among systems for LW and LDG. Feedlot heifers had greater BCS. At the beginning and end of the mating season, heifers from pasture group were heavier and had greater BCS than heifers from feedlot and supplementation.
\end{abstract}

Key Words: improved pasture, sorghum silage, supplementation

\section{Introdução}

A tendência mundial de intensificação da produção de bovinos de corte, com ênfase na redução da idade de acasalamento das novilhas, tem reflexos no Rio Grande do Sul, onde algumas propriedades rurais já utilizam, no rebanho de cria, um conjunto de práticas que resulta em vacas primíparas aos 24 meses de idade. Este tipo de acasalamento será referido no presente trabalho como sistema 'um ano'. O ponto central de interesse neste sistema está no conhecimento de que existe maior eficiência biológica nas fêmeas que parem pela primeira vez aos dois, em vez de três ou mais anos de idade (Carter \& Cox, 1973).

Quando as condições de manejo e de nutrição são adequadas, a maioria das novilhas possui potencial para atingir a puberdade e acasalar com 12 a 15 meses de idade. O sistema 'um ano' tem potencial para elevar a rentabilidade do rebanho, pois a vaca, neste sistema, produz mais quilogramas de terneiro durante sua vida (Lemeister et al., 1973). Este potencial, no entanto, depende do custo da alimentação hibernal adicional para manter a taxa adequada de crescimento das novilhas. Para a mesma taxa de prenhez, o custo alimentar pode ser bastante distinto.

\footnotetext{
1 Eng.-Agr., Dra. Professora Adjunta, Departamento de Zootecnia (UFSM)-CEP: 97119-900 - Santa Maria, RS.E.mail: mrocha@ccr.ufsm.br ${ }^{2}$ Professor Adjunto IV, Departamento de Zootecnia, Fac. de Agronomia (UFRGS), Pesq. CNPq - 1A, Caixa Postal, 776, CEP: $90001-970$. Porto Alegre, RS. E.mail: Iobato@orion.ufrgs.br
} 
É necessário o conhecimento não só das exigências nutritivas dos animais, mas também das estratégias para a construção de um sistema nutricional efetivo.

No Rio Grande do Sul, o período crítico de deficiência alimentar para o rebanho corresponde ao outono/início do inverno, quando as pastagens naturais já cessaram seu crescimento e as espécies cultivadas anuais de estação fria ainda não proporcionam condições para pastejo. No manejo do rebanho de corte, este período corresponde tradicionalmente à pós-desmama dos bezerros. Nos sistemas pecuários com utilização exclusiva de pastagens, o baixo ganho de peso das bezerras a partir desta data até o ingresso em pastagens cultivadas de estação fria é a principal limitação para alcançar taxas de crescimento anuais que permitam o seu ingresso no sistema 'um ano'. A limitação está tanto na quantidade de matéria seca quanto na proteína e energia disponíveis. Entre as estratégias para suprir estas deficiências estão a suplementação da pastagem natural, o uso de forragem conservada e a utilização de pastagens cultivadas mais cedo na sua estação de crescimento.

O uso de forragem conservada é viável onde as condições de solo, maquinário e mão-de-obra proporcionam a existência de uma integração lavourapecuária. Por outro lado, $37 \%$ da superfície do Estado do Rio Grande do Sul é coberta por pastagens naturais (Moojen, 1991) e qualquer técnica, como a suplementação, que aumente o desempenho animal sobre esta base forrageira deve ser pesquisada.

O desenvolvimento de sistemas integrados de alimentação e manejo na recria de bezerras, visando à redução da idade de acasalamento, é fundamental para o desenvolvimento da pecuária de corte no Brasil. Considerando a escassez de dados regionais sobre o manejo alimentar de fêmeas de corte para acasalamento com um ano de idade, o objetivo deste experimento foi avaliar ganho de peso e condição corporal de bezerras, desde sua desmama até o final da sua primeira estação de acasalamento, aos 14/15 meses de idade. As bezerras foram submetidas a três alternativas de alimentação no período pós-desmama: pastagem de azevém, campo nativo e suplementação com concentrado e confinamento com silagem de sorgo + nitrogênio não-protéico (NNP).

\section{Material e Métodos}

O experimento foi conduzido em uma empresa agropecuária localizada no município de Dom Pedrito, região da Campanha no Rio Grande do Sul. O clima, segundo a classificação de Köppen (Moreno, 1991), é sub-tropical úmido, da classe $\mathrm{Cfa}$. Foram utilizadas 395 bezerras de corte pertencentes a três grupos genéticos: Hereford; 3/4 Hereford -1/4 Nelore e 5/8 Hereford- 3/8 Nelore.

Após a desmama, em março de 1994, os animais permaneceram em pastagem natural melhorada com trevo branco (Trifolium repens) e cornichão (Lotus corniculatus) até $02 / 06$, quando, equilibrados por grupo racial e idade da mãe, foram manejados por 88 dias em três tratamentos alimentares: pastagempastejo contínuo em pastagem de azevém (L. multiflorum Lam.); suplementação - pastejo contínuo em pastagem natural e suplementação com concentrado; confinamento- confinamento, a céu aberto, recebendo à vontade, silagem de sorgo + nitrogênio não proteico (NNP) .

As novilhas da pastagem $(\mathrm{n}=143)$ foram manejadas em azevém com disponibilidade média de $1100 \mathrm{~kg} / \mathrm{ha}$ de matéria seca (MS) e carga animal média de $350 \mathrm{~kg} / \mathrm{ha}$ de peso vivo (PV). O azevém foi estabelecido em início de março, através de sobre-semeadura realizada com avião, sobre área preparada para plantio direto de arroz na primavera seguinte. A pastagem foi adubada com nitrogênio, na forma de uréia, na quantidade de $100 \mathrm{~kg} / \mathrm{ha}$, em duas aplicações.

As novilhas da suplementação $(n=119)$ permaneceram em pastagem natural e foram suplementadas com concentrado comercial (18\% de proteína bruta (PB) e $72 \%$ de NDT), na quantidade diária de 1,5\% em MS do PV dos animais, ajustada a cada 28 dias. O concentrado foi ofertado às $14 \mathrm{~h}$, diariamente. $\mathrm{O}$ campo nativo foi roçado $\mathrm{e}$ permaneceu diferido por 45 dias antes da entrada dos animais na área. Durante o período experimental, a disponibilidade média de MS da pastagem foi de $900 \mathrm{~kg} / \mathrm{ha}$ e a carga animal média, de $220 \mathrm{~kg} / \mathrm{ha} \mathrm{de}$ $\mathrm{PV}$. As espécies predominantes na pastagem natural são de crescimento estival, sendo a maior ocorrência de gramíneas dos gêneros Paspalum e Axonopus e leguminosas dos gêneros Trifolium e Desmodium.

Os animais do grupo confinamento $(\mathrm{n}=133)$ receberam silagem de sorgo ( $30 \% \mathrm{MS}, 5,2 \%$ de $\mathrm{PB}$ e $61 \%$ de NDT) à vontade. A quantidade 'alvo' de $\mathrm{NNP} /$ bezerra/dia foi de $0,1 \mathrm{~kg}$, sendo uma mistura de uréia + sulfato de amônio, na proporção de 9:1. Os animais permaneceram em uma área de 10 ha. O alimento foi distribuído às 9 e $15 \mathrm{~h}$.

Após a aplicação dos três sistemas alimentares,

R. Bras. Zootec., v.31, n.4, p.1814-1822, 2002 
as novilhas permaneceram como um só rebanho, em pastagem melhorada com azevém, trevo branco e cornichão. Todos animais tiveram acesso à mistura mineral à vontade e foram submetidas a rigoroso controle sanitário.

A disponibilidade de matéria seca nas pastagens foi medida pela técnica da dupla amostragem (Gardner, 1986). Da silagem, concentrado comercial e amostras de forragem obtidas foram retiradas amostras compostas para a determinação do teor de MS e PB, pelo método micro Kjedahl (AOAC, 1984) e usando a metodologia de Tilley \& Terry (1963) para a determinação da digestibilidade in vitro da matéria seca e orgânica (DIVMS e DIVMO).

As pesagens foram realizadas após jejum de doze horas. Em cada pesagem as bezerras foram submetidas a avaliações visuais de escore de condição corporal (CC), por dois avaliadores, utilizando uma escala de cinco pontos, adaptada da classificação de Lowman et al. (1976), em que condição 1 = magra; condição 5 = gorda.

Os tratamentos foram avaliados em termos de ganho de peso médio diário (GMD), evolução da CC e PV. A análise estatística foi realizada pelo procedimento GLM (General Linear Model) do pacote computacional SAS (Statistical Analysis System, 1990), versão 6.08. As médias foram comparadas pelo teste de Tukey, a 5\% de significância.

\section{Resultados e Discussão}

O peso médio e a condição corporal das bezerras, ajustados por covariância, no início da aplicação dos tratamentos, foram de $155,5 \mathrm{~kg}$ e 3,14 , respectivamente. A idade média inicial foi de 250 dias. O PV, GMD e CC, durante a aplicação dos tratamentos, são apresentados na Tabela 1.

Os sistemas alimentares não determinaram diferenças $(\mathrm{P}>0,05)$ no GMD no final do período de aplicação, mas foi diferente $(\mathrm{P}<0,05)$ nos períodos inicial e intermediário, refletindo a adaptação dos animais às mudanças no seu regime alimentar. $\mathrm{O}$ GMD realizado pelas bezerras após sua desmama, cerca de 400 gramas, assemelha-se ao GMD de 466

Tabela 1 - Ganho diário médio de peso (GMD), médias de peso vivo (PV) e condição corporal (CC) de bezerras de corte nos sistemas alimentares no primeiro inverno pós-desmama (02/06-28/08/1994)

Table 1 - Live weight daily gain (LDG), average live weight (LW) and body condition score (BCS) of beef heifers in feeding systems during the first winter post-weaning period (06/02-08/28/1994)

\begin{tabular}{|c|c|c|c|c|}
\hline \multirow[t]{2}{*}{$\begin{array}{l}\text { Parâmetros/Período } \\
\text { Parameters/Period }\end{array}$} & \multicolumn{3}{|c|}{$\begin{array}{l}\text { Sistema alimentar } \\
\text { Feeding system }\end{array}$} & \multirow[t]{2}{*}{$\begin{array}{l}\text { Média } \\
\text { Mean }\end{array}$} \\
\hline & $\begin{array}{l}\text { Pastagem } \\
\text { Pasture }\end{array}$ & $\begin{array}{l}\text { Suplementação } \\
\text { Supplementation }\end{array}$ & $\begin{array}{c}\text { Confinamento } \\
\text { Feedlot }\end{array}$ & \\
\hline \multicolumn{5}{|l|}{$\begin{array}{l}\mathrm{PV}, \mathrm{kg} \text { (dias) } \\
\text { Live weight, } \mathrm{kg} \text { (days) }\end{array}$} \\
\hline $\begin{array}{l}28 \\
55 \\
88 \\
\text { Média } \\
\text { Mean }\end{array}$ & $\begin{array}{l}167,97^{\mathrm{a}} \\
181,37^{\mathrm{a}} \\
189,52^{\mathrm{a}} \\
179,62^{\mathrm{a}}\end{array}$ & $\begin{array}{l}158,86^{\mathrm{c}} \\
174,09^{\mathrm{b}} \\
192,84^{\mathrm{a}} \\
175,26^{\mathrm{a}}\end{array}$ & $\begin{array}{l}161,98^{\mathrm{b}} \\
175,48^{\mathrm{b}} \\
191,38^{\mathrm{a}} \\
176,28^{\mathrm{a}}\end{array}$ & $\begin{array}{l}163,18 \\
177,41 \\
191,25\end{array}$ \\
\hline $\begin{array}{l}\text { GMD, } \mathrm{kg} \text { (dias) } \\
L D G, \mathrm{~kg} \text { (days) }\end{array}$ & & & & \\
\hline $\begin{array}{l}0-28 \\
29-55 \\
56-88 \\
0-88\end{array}$ & $\begin{array}{l}0,445^{\mathrm{a}} \\
0,496^{\mathrm{b}} \\
0,254^{\mathrm{c}} \\
0,390^{\mathrm{a}}\end{array}$ & $\begin{array}{l}0,120^{\mathrm{c}} \\
0,563^{\mathrm{a}} \\
0,586^{\mathrm{a}} \\
0,429^{\mathrm{a}}\end{array}$ & $\begin{array}{l}0,231^{\mathrm{b}} \\
0,500^{\mathrm{b}} \\
0,496^{\mathrm{b}} \\
0,412^{\mathrm{a}}\end{array}$ & $\begin{array}{l}0,265 \\
0,519 \\
0,445\end{array}$ \\
\hline $\begin{array}{l}C C(1-5)(\text { dias }) \\
B C S(1-5) \text { (days) }\end{array}$ & & & & \\
\hline $\begin{array}{l}28 \\
55 \\
88 \\
\text { Média }\end{array}$ & $\begin{array}{l}2,9^{\mathrm{a}} \\
3,1^{\mathrm{a}} \\
3,2^{\mathrm{b}} \\
3,0^{\mathrm{b}}\end{array}$ & $\begin{array}{l}2,9^{\mathrm{a}} \\
3,0^{\mathrm{b}} \\
3,2^{\mathrm{b}} \\
3,0^{\mathrm{b}}\end{array}$ & $\begin{array}{l}2,9^{\mathrm{a}} \\
3,1^{\mathrm{a}} \\
3,3^{\mathrm{a}} \\
3,1^{\mathrm{a}}\end{array}$ & $\begin{array}{l}2,9 \\
3,0 \\
3,2\end{array}$ \\
\hline
\end{tabular}

$a, b, c$ Valores seguidos por letras distintas na mesma linha diferem $(P<0,05)$.

$a, b, c$ Values followed by different letters in the same row differ $(P<.05)$.

R. Bras. Zootec., v.31, n.4, p.1814-1822, 2002 
gramas/dia, para este mesmo período, recomendado por Fox et al. (1988), para que fêmeas bovinas com peso adulto de $467 \mathrm{~kg}$ possam ingressar no sistema 'um ano'.

$\mathrm{Na}$ Tabela 2 encontram-se a massa de forragem disponível, em $\mathrm{kg} / \mathrm{ha}$ de MS, o teor de proteína bruta e digestibilidade in vitro da matéria orgânica de amostras de forragem coletadas no decorrer do experimento.

Os maiores GMD observados para os animais em pastagem de azevém, na fase inicial, refletem a maior facilidade de adaptação dos animais que anteriormente também se encontravam em pastagens. Estes ganhos declinaram no período final, acompanhando o decréscimo na massa de forragem (Tabela 2), pois a MF é um dos fatores primários influenciando o consumo de animais em pastejo. O desempenho destes animais está diretamente associado com a quantidade de MS consumida e a qualidade da pastagem (Blaser, 1990).

Conforme Dougherty (1999), no entanto, é difícil prever a qualidade da forragem consumida por animais em pastejo a partir de estimativas do valor nutritivo da forragem oferecida. Como os teores de $\mathrm{PB}$ encontrados na $\mathrm{MF}$ não são limitantes para ganhos de até 900 gramas, para animais desta categoria com peso médio de $181 \mathrm{~kg}$ (NRC, 1984), os animais certamente estiveram limitados pela quantidade de MS e energia necessárias para ganhos mais expressivos. A pastagem de azevém apresentou MF média de $1100 \mathrm{~kg} / \mathrm{ha}$ de MS, inferior aos $1500 \mathrm{~kg}$ de MS/ha recomendado para aveia para máximo ganho de peso por animal (Gardner et al., 1982). Nos meses de junho a julho, a utilização de pastagens ditas de estação fria é prejudicada, pois seu crescimento é quase nulo em temperaturas inferiores a $10^{\circ} \mathrm{C}$ (Jacques, 1993). O azevém, reconhecidamente, tem seu maior período de crescimento mais tarde na estação.

Considerando todo o período, animais suplementados em campo nativo apresentaram GDM de $0,429 \mathrm{~kg}$, semelhante $(\mathrm{P}>0,05)$ aos animais dos outros tratamentos. Sem suplementação, exclusivamente em pastagem natural, a perda de peso estaria ao redor de 200 a 300 gramas/animal/dia (Moojen, 1991). Em forragem de baixa qualidade, melhor desempenho animal com a suplementação pode ser devido a: maior consumo de energia com o consumo de suplemento; a porção protéica provê a microflora ruminal com $\mathrm{N}$ amoniacal e aminoácidos (AA); e uma porção da proteína escapa da degradação ruminal e supre AA adicionais para o intestino delgado (Ferrel et al., 1999). O GMD das bezerras no campo suplementado, no entanto, foi inferior ao ganho proporcionado pelos outros tratamentos no primeiro período de 0 a 28 dias e superior nos períodos seguintes, 29 a 88 dias. Com animais adaptados previamente ao consumo de suplementos e fornecimento de $1,5 \%$ do PV das bezerras, em MS, de um concentrado com $21 \%$ de $\mathrm{PB}$ e $82 \%$ de NDT, em pastagem natural,

Tabela 2 - Valores da massa de forragem (MF), conteúdo de proteína bruta (PB) e da digestibilidade in vitro da matéria orgânica (DIVMO) das amostras de forragem, conforme os sistemas alimentares

Table 2 - Forage availability (FM), crude protein (CP) value and in vitro dry matter digestibility (IVDMD) of forage samples from the feeding systems

\begin{tabular}{|c|c|c|c|c|c|c|c|c|c|}
\hline & \multicolumn{9}{|c|}{$\begin{array}{c}\text { Tratamentos } \\
\text { Treatments } \\
\end{array}$} \\
\hline & \multicolumn{3}{|c|}{$\begin{array}{l}\text { Pastagem } \\
\text { Pasture }\end{array}$} & \multicolumn{3}{|c|}{$\begin{array}{l}\text { Suplementação } \\
\text { Supplementation }\end{array}$} & \multicolumn{3}{|c|}{$\begin{array}{l}\text { Pastagem melhorada } \\
\text { Improved pasture }\end{array}$} \\
\hline \multirow[t]{3}{*}{$\begin{array}{l}\text { Datas de corte } \\
\text { Dates of cut }\end{array}$} & & & & \multicolumn{3}{|c|}{$\begin{array}{l}\text { Parâmetros } \\
\text { Parameters }\end{array}$} & & & \\
\hline & $\mathrm{MF}$ & PB & DIVMO & $\mathrm{MF}$ & PB & DIVMO & $\mathrm{MF}$ & PB & DIVMO \\
\hline & $\begin{array}{c}F M \\
\mathrm{~kg} / \mathrm{ha}\end{array}$ & $C P$ & $\begin{array}{c}I V D O M \\
\%\end{array}$ & $\begin{array}{c}D M \\
\%\end{array}$ & $\begin{array}{c}C P \\
\mathrm{~kg} / \mathrm{ha}\end{array}$ & $\begin{array}{c}I V D O M \\
\%\end{array}$ & $\begin{array}{c}F M \\
\%\end{array}$ & $C P$ & IVDOM \\
\hline 03/06/1994 & 1100 & 12,3 & 58,2 & 900 & 6,2 & 35,6 & & & \\
\hline 26/07/1994 & 1050 & 12,3 & 54,6 & 910 & 6,3 & 30,4 & & & \\
\hline 20/08/1994 & 938 & 13,9 & 53,0 & 890 & 6,9 & 38,0 & & & \\
\hline 05/09/1994 & & & & & & & 1200 & 11,6 & 54,1 \\
\hline 07/10/1994 & & & & & & & 1600 & 10,7 & 52,0 \\
\hline 13/11/1994 & & & & & & & 4032 & 10,7 & 47,2 \\
\hline 05/12/1994 & & & & & & & 3200 & 6,3 & 31,3 \\
\hline 20/01/1995 & & & & & & & 2700 & 7,3 & 32,6 \\
\hline
\end{tabular}

R. Bras. Zootec., v.31, n.4, p.1814-1822, 2002 
Beretta \& Lobato (1998) observaram GMD de $0,615 \mathrm{~kg} /$ dia em animais Angus e Hereford, no outono/inverno. No presente trabalho, o período de adaptação dos animais à suplementação no campo nativo foi bem superior ao período de adaptação dos animais nos tratamentos Confinamento e Pastagem, justificando o GMD inferior destes animais no período inicial. Os programas de suplementação assumem a suposição de que os animais consomem individualmente uma quantidade 'alvo' do suplemento. Este método não considera a variação individual no consumo (Lobato et al., 1980) e os problemas potenciais, se o suplemento não é consumido na quantidade proposta. O desvio da quantidade programada para ser consumida pode afetar de forma negativa a produção animal (Bowman \& Sowell, 1997).

Os animais mantidos em confinamento tiveram menores dificuldades na adaptação ao novo sistema alimentar. A rapidez de adaptação dos animais à silagem provavelmente ocorreu devido à não existência no local de alimentação de outro tipo de alimento, como pastagem, que pudesse ser consumido preferencialmente à silagem. Neste tratamento, para a quantidade de nitrogênio não protéico fornecido, $0,10 \mathrm{~kg} / \mathrm{cab} . / \mathrm{dia}$, certamente existiu muita variação no consumo individual com relação à quantidade 'alvo'. Esta quantidade é pequena, proporcionalmente à quantidade média de silagem consumida por bezerra, $20 \mathrm{~kg} / \mathrm{cab}$./dia, e dificulta uma mistura homogênea. A silagem de sorgo apresentava teor médio de PB de 5,22\%, e este nitrogênio, quando somado ao NNP das 100 gramas/cabeça/dia da mistura uréia+sulfato de amônio, foi suficiente para assegurar o GMD de $0,412 \mathrm{~kg} / \mathrm{cab}$./dia, nesta categoria. A energia presente na silagem poderia ter proporcionado ganho um pouco mais elevado (NRC, 1984).

Para peso corporal, em kg, os tratamentos determinaram diferença $(\mathrm{P}<0,01)$ nas pesagens realizadas em 30/06 e 27/07 e não determinaram diferença $(\mathrm{P}>0,05)$ na pesagem realizada em $28 / 08$. Pesos vivos semelhantes, no final do inverno, nos diferentes sistemas, mostram o seu potencial similar para suprir as deficiências alimentares do rebanho nesta época. Para a mesma taxa de ganho, no entanto, o custo alimentar pode ser bastante distinto. O uso de pastagens como fonte primária de energia para bovinos de corte tem vantagens econômicas.

No final da aplicação dos tratamentos, a diferença existente foi de apenas 3,3 kg entre o maior $(192,8 \mathrm{~kg}$; suplementação) e o menor peso médio $(189,5 \mathrm{~kg}$; pastagem). Os pesos no final do inverno podem ser considerados bastante baixos para o sistema 'um ano' e resultam de pesos já baixos na desmama e ganhos moderados no outono/inverno. Pesos similares para sistema 'um ano' foram relatados por Beretta \& Lobato (1998) e resultaram de pesos ainda mais baixos à desmama que os do presente trabalho, mas ganhos mais elevados no outono/inverno.

Os sistemas alimentares não determinaram diferença $(\mathrm{P}>0,05)$ para $\mathrm{CC}$ em $30 / 06$, mas determinaram diferença $(\mathrm{P}<0,01)$ em $27 / 07$ e $28 / 08$. Animais alimentados com silagem + NNP apresentaram CC superior $(\mathrm{P}<0,01)$ aos animais provenientes da pastagem de azevém e do campo nativo suplementado, e estes não diferiram entre si $(\mathrm{P}>0,05)$. Esta propensão para estocar energia nas novilhas do confinamento pode ser importante no estabelecimento da CC necessária para prenhez aos 14-15 meses de idade. Para desempenho reprodutivo satisfatório, esta deposição de gordura é fundamental. O sorgo do qual foi confeccionada a silagem apresentou alto percentual de grãos na massa ensilada ( $40 \%$ de panícula em relação ao pé inteiro, na MS), o que pode justificar o resultado obtido. Este resultado, sistemas alimentares propiciando CC distintas, é diferente do reportado por Beretta \& Lobato (1998), que observaram que o $\mathrm{PV}$ e a altura da garupa foram os mais afetados pelos sistemas alimentares que a CC. Considerando um ganho médio de $36 \mathrm{~kg} /$ cabeça realizado em 88 dias, o acréscimo percentual na CC durante a aplicação dos tratamentos, $0,06 \%$, é bastante pequeno e demonstra a importância de animais com boa CC já na desmama, pois diferenças em peso e condição corporal antes da primeira estação de monta permanecem no parto (Patterson et al., 1992).

Os pesos, CC e GMD após o término dos sistemas alimentares e até o início do acasalamento estão relacionados na Tabela 3 . As bezerras que saíram dos tratamentos alimentares do outono/inverno, em condições similares de peso $(\mathrm{P}>0,05)$, passam a ter seu peso bastante diferenciado no mês seguinte ao término dos tratamentos.

No período de 28/08 a 06/10, bezerras oriundas dos tratamentos pastagem, suplementação e confinamento foram colocadas em um só lote em campo nativo melhorado. Neste período, o GMD dos animais da pastagem, que havia sido, no período anterior, de apenas de 0,254 , foi de $0,695 \mathrm{~kg} / \mathrm{dia}, 2,7$ e 2,2 vezes maiores que os ganhos de 0,254 e 0,311 $\mathrm{kg} /$ dia realizados pelos animais dos tratamentos

R. Bras. Zootec., v.31, n.4, p.1814-1822, 2002 
Tabela 3 - Ganho médio diário (GMD), peso vivo médio (PV) e condição corporal média (CC) no período após a aplicação dos tratamentos pós-desmama até o início do acasalamento (28/08/94-08/11/94)

Table 3 - Live weight daily gain (LDG), average live weight (LW) and body condition score (BCS) since the end of feeding systems to the beginning of the mating season (08/28/94-11/08/94)

\begin{tabular}{|c|c|c|c|c|}
\hline \multirow[t]{2}{*}{$\begin{array}{l}\text { Parâmetros/Período } \\
\text { Parameters/Period }\end{array}$} & \multicolumn{3}{|c|}{$\begin{array}{l}\text { Sistemas alimentares } \\
\text { Feedings systems }\end{array}$} & \multirow[t]{2}{*}{$\begin{array}{l}\text { Média } \\
\text { Mean }\end{array}$} \\
\hline & $\begin{array}{c}\text { Pastagem } \\
\text { Pasture }\end{array}$ & $\begin{array}{l}\text { Suplementação } \\
\text { Supplementation }\end{array}$ & $\begin{array}{c}\text { Confinamento } \\
\text { Feedlot }\end{array}$ & \\
\hline \multicolumn{5}{|l|}{ GDM, kg(dias) } \\
\hline $\begin{array}{l}88-127 \\
128-160 \\
\text { Média } \\
\text { Mean }\end{array}$ & $\begin{array}{l}0,695^{\mathrm{a}} \\
0,929^{\mathrm{b}} \\
0,802^{\mathrm{a}}\end{array}$ & $\begin{array}{l}0,254^{\mathrm{c}} \\
0,985^{\mathrm{a}} \\
0,589^{\mathrm{b}}\end{array}$ & $\begin{array}{l}0,311^{\mathrm{b}} \\
0,951^{\mathrm{b}} \\
0,604^{\mathrm{b}}\end{array}$ & $\begin{array}{l}0,436 \\
0,954 \\
0,674\end{array}$ \\
\hline \multicolumn{5}{|l|}{$\mathrm{PV}, \mathrm{kg}($ dias $)$} \\
\hline $\begin{array}{l}88 \\
127 \\
160\end{array}$ & $\begin{array}{l}189,52^{\mathrm{a}} \\
216,50^{\mathrm{a}} \\
247,41^{\mathrm{a}}\end{array}$ & $\begin{array}{l}192,84^{\mathrm{a}} \\
203,13^{\mathrm{b}} \\
235,42^{\mathrm{b}}\end{array}$ & $\begin{array}{l}191,38^{\mathrm{a}} \\
203,23^{\mathrm{b}} \\
234,83^{\mathrm{b}}\end{array}$ & $\begin{array}{l}191,25 \\
208,29 \\
239,78\end{array}$ \\
\hline \multicolumn{5}{|c|}{$\mathrm{CC}(1-5) \quad($ dias $)$} \\
\hline $\begin{array}{l}88 \\
127 \\
160\end{array}$ & $\begin{array}{l}3,20^{\mathrm{b}} \\
3,50^{\mathrm{a}} \\
3,60^{\mathrm{a}}\end{array}$ & $\begin{array}{l}3,20^{\mathrm{b}} \\
3,40^{\mathrm{b}} \\
3,40^{\mathrm{c}}\end{array}$ & $\begin{array}{l}3,30^{\mathrm{a}} \\
3,40^{\mathrm{b}} \\
3,50^{\mathrm{b}}\end{array}$ & $\begin{array}{l}3,30 \\
3,40 \\
3,50\end{array}$ \\
\hline
\end{tabular}

$\mathrm{a}, \mathrm{b}$ Valores seguidos por letras distintas na mesma linha diferem estatisticamente $(\mathrm{P}<0,01)$

$a, b$ Values followed by different letters in the same line differ statistically $(P<0.01)$

suplementação e confinamento, respectivamente. Em conseqüência do GMD realizado nesta fase, o peso das novilhas oriundas da pastagem foi superior $(\mathrm{P}>0,05)$ aos demais no início do acasalamento. Os ganhos realizados em pastagem na primavera freqüentemente estão relacionados de forma inversa com os ganhos realizados no inverno (Wanyoke \& Holmes, 1991; Beretta \& Lobato, 1998). Quanto maior o ganho realizado no inverno, maior será o decréscimo linear do ganho em pastagens, conforme Lewis et al.(1990). Estes autores observaram, para cada 100 gramas de ganho adicional no inverno, redução no ganho em pastagem de 81 gramas. Resultados similares ao do presente trabalho foram observados por Beretta \& Lobato (1998), que observaram o PV das novilhas no início da estação de monta significativamente afetado pelo sistema de alimentação hibernal. Novilhas confinadas chegaram ao acasalamento com menor peso do que a média das novilhas em pastagem e suplementadas, em decorrência das diferenças em GMD durante a primavera. Durante a transição do regime de confinamento para pastagens, a mudança de dieta e período de readaptação da flora ruminal às novas condições de alimentação prejudicou as novilhas deste tratamento em maior magnitude. Granger et al. (1990) observaram, em novilhas consumindo somente feno durante o inverno, ganhos $29 \%$ superiores em pastejo de azevém do que novilhas que receberam concentrados durante o inverno. O maior GMD observado em novilhas com menor GMD em fase anterior é denominado por Ryan (1990) de 'crescimento compensatório' e definido como uma taxa de crescimento superior à taxa de crescimento normal, observada algumas vezes após um período no qual uma restrição nutricional é imposta aos animais. Um consumo aumentado em proporção ao PV durante o período de realimentação é citado freqüentemente como o principal fator contribuindo para a maior taxa de ganho (Lewis et al., 1990). Conforme Fox et al. (1972), o crescimento compensatório envolve a redução na exigência de megacalorias para mantença e o aumento na eficiência no uso da energia metabolizável acima da mantença. A oportunidade de manejar bezerras desmamadas com entrada mínima de alimentos durante o inverno, e, então, tirar vantagens do crescimento compensatório quando a forragem verde estiver disponível, pode ter vantagens econômicas (Lalman et al., 1993).

A vantagem em $\mathrm{CC}$ dos animais oriundos da silagem $(C C=3,3)$ desaparece no período após o final 
da suplementação e, em função do maior ganho $(\mathrm{P}<0,01)$ dos animais da pastagem nesta ocasião, estes passam a ter maior $\mathrm{CC}(3,6 ; \mathrm{P}<0,01)$ no início do acasalamento.

$\mathrm{Na}$ Tabela 4 estão relacionados os pesos médios inicial e final e o ganho médio diário durante o acasalamento (10/11/1994 a 25/01/1995), conforme tratamentos alimentares no outono/inverno pós-desmama. O período de avaliação das bezerras no acasalamento foi de 10/11/1994 a 25/01/1995, totalizando 77 dias.

Durante o acasalamento, as novilhas oriundas do tratamento confinamento realizaram GMD superior $(\mathrm{P}<0,05)$ ao GMD de suas contemporâneas dos tratamentos pastagem e suplementação, as quais também diferiram entre $\mathrm{si}(\mathrm{P}<0,05)$. Este maior GMD, no entanto, não foi suficiente para compensar o menor PV destas novilhas no início do acasalamento.

Novilhas que receberam somente pastagens desde a desmama pesaram mais durante o período de acasalamento $(\mathrm{P}<0,01)$ do que suas contemporâneas alimentadas na pós-desmama com campo nativo + suplementação ou silagem + NNP, e estas não diferiram entre si $(\mathrm{P}>0,05)$. $\mathrm{O}$ ganho realizado pelas novilhas do tratamento pastagem no final do inverno/ início da primavera fez com que a vantagem deste tratamento, em PV, persistisse até o final do acasalamento. Sawyer et al. (1991) categorizaram pesos no início do acasalamento para novilhas cruzas Devon e Hereford no sistema 'um ano' e os relacionaram com porcentagem de parição. Os baixos pesos iniciais das novilhas do presente trabalho enquadraramse na categoria dois dos autores $(220-250 \mathrm{~kg})$ e para estes animais seria esperada uma parição de 43-50\%.

Grande número de estudos mostrou uma relação positiva entre PV no primeiro acasalamento e taxa de natalidade subseqüente (Carter \& Cox, 1973). A economicidade do peso, no início do acasalamento, dentro de cada tratamento, depende do valor marginal de bezerros e alimentos, que podem ser suplementos bastante caros, quando a disponibilidade e qualidade das pastagens são limitantes. No sistema 'um ano', durante 180-210 dias, entre a desmama e o acasalamento, a novilha deve realizar ganho de $25 \%$ do seu peso adulto, pressupondo que ela tenha cerca de $40 \%$ deste peso por ocasião da desmama e deva atingir $65 \%$ no acasalamento. Este sistema é bem mais dependente do nível de nutrição pós-desmama do que o sistema de acasalamento aos 24 meses, em que o ganho idêntico deve ser realizado em aproximadamente 18 meses (Marshall, 1981).

A CC média de 3,54, no início do acasalamento, foi

Tabela 4 - Ganho médio diário (GMD), peso vivo médio (PV) e condição corporal média (CC) do início até o final do acasalamento (10/11/94-25/01/95) de novilhas submetidas a sistemas alimentares na pós-desmama

Table 4 - Live weight daily gain (LDG), average live weight (LW) and body condition score (BCS) since the beginning until the end of the mating season (11/10/94-01/25/95) of beef heifers submitted to feeding systems during post-weaning period

Parâmetros/Período

Parameters/Period

Sistemas alimentares

Média

Feedings systems

Mean

\begin{tabular}{|c|c|c|c|c|}
\hline & $\begin{array}{c}\text { Pastagem } \\
\text { Pasture }\end{array}$ & $\begin{array}{l}\text { Suplementação } \\
\text { Supplementation }\end{array}$ & $\begin{array}{l}\text { Confinamento } \\
\text { Feedlot }\end{array}$ & \\
\hline $\begin{array}{l}\text { GDM, } \mathrm{kg} \text { (dias) } \\
L D G, \operatorname{kg} \text { (days) }\end{array}$ & $0,465^{\mathrm{c}}$ & $0,496^{\mathrm{b}}$ & $0,529^{\mathrm{a}}$ & 0,496 \\
\hline $\begin{array}{l}\mathrm{PV}, \mathrm{kg} \\
\text { Live weight }(\mathrm{kg})\end{array}$ & & & & \\
\hline $\begin{array}{l}\text { Inicial } \\
\text { Initial }\end{array}$ & $248,34^{\mathrm{a}}$ & $283,21^{\mathrm{a}}$ & $235,88^{\mathrm{b}}$ & 240,21 \\
\hline $\begin{array}{l}\text { Final } \\
\text { Final } \\
\mathrm{CC}^{1}\end{array}$ & $283,21^{\mathrm{a}}$ & $273,61^{b}$ & $275,55^{\mathrm{b}}$ & 277,45 \\
\hline Body condition score & & & & \\
\hline $\begin{array}{l}\text { Inicial } \\
\text { Initial }\end{array}$ & $3,60^{\mathrm{a}}$ & $3,40^{\mathrm{c}}$ & $3,50^{\mathrm{b}}$ & 3,54 \\
\hline $\begin{array}{l}\text { Final } \\
\text { Final }\end{array}$ & $3,81^{\mathrm{a}}$ & $3,68^{\mathrm{b}}$ & $3,74^{\mathrm{b}}$ & 3,74 \\
\hline
\end{tabular}

$a, b, c$ Valores seguidos por letras distintas na mesma linha diferem estatisticamente $(P<0,05)$

$a, b, c$ Values followed by different letters in the same line differ statistically $(P<0.01)$

R. Bras. Zootec., v.31, n.4, p.1814-1822, 2002 
superior à condição corporal de 3 (escala de 1-5), considerada desejável para novilhas leiteiras de reposição, no período compreendido entre os três meses de idade e o acasalamento (Noller, 1997). Animais do tratamento pastagem apresentaram $\mathrm{CC}$, no início do acasalamento, superior $(\mathrm{P}<0,01)$ aos animais da suplementação e animais do confinamento apresentavam $C C$ superior $(\mathrm{P}<0,01)$ aos suplementados em pastagem natural. Os animais de todos os tratamentos, no entanto, apresentaram $\mathrm{CC}$ inferior às relatadas por Semmellmann et al. (2001), em animais Nelore com 17-18 meses de idade, também no início da estação de acasalamento. No final do acasalamento, animais do tratamento pastagem permaneciam com $\mathrm{CC}$ superior aos animais dos outros tratamentos $(\mathrm{P}<0,01)$, mas estes já não diferiam entre si $(\mathrm{P}>0,05)$. A CC, que permite avaliar subjetivamente a quantidade de tecido adiposo depositado, constitui um dos indicadores do estado nutricional que mais diretamente se associa com a percentagem de prenhez (Rice, 1991). No período de acasalamento, foi observada uma mudança de CC de 0,2 pontos. Com dados coletados na Autralia, Sawyer et al. (1991) relataram para 100 dias de acasalamento mudanças de 0,09 e 0,87 unidades em animais das raças Hereford e Simmental, respectivamente, demonstrando que os animais deste experimento mostraram bom acréscimo na sua condição corporal.

\section{Conclusões}

É possível atingir desenvolvimento adequado para que bezerras de corte possam ser acasaladas aos 14/15 meses de idade, utilizando-se diferentes sistemas alimentares no primeiro outono/inverno pós-desmama.

Para ganho diário médio similar de bezerras em pastejo ou recebendo alimentação no cocho, o período de transição destes sistemas para alimentação em pastagens afeta de forma diferenciada o desempenho dos animais, favorecendo animais em regime exclusivo de pasto.

Animais alimentados exclusivamente em pastagens desde a sua desmama até o final do primeiro acasalamento mostram maior peso vivo e condição corporal do que animais que foram suplementados em campo nativo ou alimentados com silagem de sorgo + NNP no primeiro outono/ inverno pós-desmama.

\section{Agradecimento}

Ao MédicoVeterinário Valter José Potter, proprietário da Empresa Agropecuária Guatambu, pelo financiamento do trabalho e pela cessão das instalações. Ao MédicoVeterinário Adriano Garcia Rosado Jr. e à Zootecnista Luciana Pötter, pelo auxílio na coleta dos dados experimentais.

\section{Literatura Citada}

ASSOCIATION OF OFFICIAL ANALYTICAL CHEMISTS AOAC. Official methods of analysis. 14. ed. Washington, D.C.: $1984.1141 \mathrm{p}$.

BERETTA, V.; LOBATO, J.F.P. Sistema "um ano" de produção de carne: avaliação de estratégias alternativas de alimentação hibernal de novilhas de reposição. Revista Brasileira de Zootecnia, v.27, n.1, p.157-163, 1998

BLASER, R.E. Manejo do complexo pastagem-animal para avaliação de plantas e desenvolvimento de sistemas de produção de forragens. In: PASTAGENS-FUNDAMENTOS DA EXPLORAÇÃO RACIONAL, 1990, Piracicaba. Anais... Piracicaba: Fundação de Estudos Agrários "Luiz de Queiroz", 1993. p. 157-205.

BOWMAN, J.G.P.; SOWELL, B.F. Delivery method and supplement consumption by grazing ruminants : a review. Journal of Animal Science, v.75, n.2, p.543-550, 1997.

CARTER, A.H.; COX, E.H. Observations on yearling mating of beef cattle. In: NEW ZEALAND SOCIETY OF ANIMAL PRODUCCTION, 33., 1973, Palmerston North. Proceedings... Palmerston North: NZSAP, 1973. p.94-113.

DOUGHERTY, C.T. New approaches to research at the plantanimal interface of grazing beef cattle. In: REUNIÃO DA SOCIEDADE BRASILEIRA DE ZOOTECNIA, 36, 1999 , Porto Alegre. Anais...Porto Alegre: Sociedade Brasileira de Zootenia, 1999. p.333-343.

FERREL, C.L.; KREIKEMEIER, A.; FREETLY, H.C. The effect of supplemental energy, nitrogen and protein on feed intake, digestibility and nitrogen flux across the gut and liver in sheep fed low quality forage. Journal of Animal Science, v.77, n.12, p.3353-3364, 1999.

FOX, D.G.; JOHNSON, R.R.; PRESTON, R.L. et al. Protein and energy utilization during compensatory growth in beef cattle. Journal of Animal Science, v.38, n.3, p.437-45, 1972.

FOX, D.G.; SNIFFEN, C.J.; O'CONNOR, J.D. Adjusting nutrient requirements of beef cattle for animal and environmental variations. Journal of Animal Science, v.66, n.6, p.475-495, 1988.

GARDNER, A.L. Técnicas de pesquisa em pastagem e aplicabilidade de resultados em sistemas de produção. Brasília: IICA/EMBRAPA-CNPGL，1986. 197p. (Série publicações miscelâneas, 634).

GARDNER, A.L.; PIRES, A.C.; CARVALHO, L.A. Relação entre a disponibilidade de forragem de aveia e o ganho de peso de bezerros mestiços leiteiros. Revista Brasileira de Zootecnia, v.11, n.1, p.53-69, 1982.

GRANGER, A.L.; WYATT, W.E.; HEMBRY, F.G. et al. Effects of breed and wintering diet on heifer post weaning growth and development. Journal of Animal Science, v.68, n.2, p.304-316, 1990.

JACQUES, A.V.A. Melhoramento de pastagens naturais: intro-

R. Bras. Zootec., v.31, n.4, p.1814-1822, 2002 
dução de espécies de estação fria. In: CAMPO NATIVO. MELHORAMENTO E MANEJO, 1993, Esteio. Anais ... Esteio: FEDERACITE, 1993. p.24-31.

LALMAN, D.L.; PETERSEN, M.K.; ANSOTEGUI, R.P. et al. The effects of ruminally undegradable protein, propionic acid, and monensin on puberty and pregnancy in beef heifers. Journal of Animal Science, v.71, n.10, p.2843-2852, 1993.

LESMEISTER, J.L.; BURFENING, P.J.; BLACKWELL, R.L. Date of first calving in beef cows and subsequent calf production. Journal of Animal Science, v.36, n.1, p.1-6, 1973.

LEWIS, J.M.; KLOPFENSTEIN, T.J.; STOCK, R.A. Effects of rate of gain during winter on subsequent grazing and finishing performance. Journal of Animal Science, v.68, n.8, p.25252529, 1990.

LOBATO, J.F.P.; PEARCE, G.R.; TRIBE, D.E. Measurement of the variability in intake by sheep of oat grain, hay and molasses-urea blocks using chromic oxide as a marker. Australian Journal of Experimental Agricultural Animal Husbandry, v.20, p.413-416, 1980.

LOWMAN, B.G.; SCOTT, N.; SOMERVILLE, S. Condition scoring beef cattle. Edinburgh: East of Scotland College of Agriculture, 1976. 8p. (Bulletin 6).

MARSHALL, T.T. Managing heifers in Florida to calve first at two years of age In: BEEF CATTLE SHORT COURSE, 1991, Gaynesville. Proceedings...Gaynesville: Institute of Food and Agricultural Sciences, University of Florida, 1981. p.176-178.

MOOJEN, E.L. Dinâmica e potencial produtivo de uma pastagem nativa do Rio Grande do Sul submetida a pressões de pastejo, épocas de diferimento e níveis de adubação. Porto Alegre: Universidade Federal do Rio Grande do Sul, 1991. 172p. Tese (Doutorado em Forragicultura) Universidade Federal do Rio Grande do Sul, 1991.

MORENO, J.A. Clima do Rio Grande do Sul. Porto Alegre: Secretaria da Agricultura, 1961.41p.

NATIONAL RESEARCH COUNCIL - NRC. Nutrient requirements of beef cattle. 6.ed. Washington, D.C.: 1984. 158p.

NOLLER, C.R. Nutritional requirements of the grazing animal. In: SIMPÓSIO INTERNACIONAL SOBRE PRODUÇÃO ANIMAL EM PASTEJO, 1997, Viçosa, MG. Anais... Viçosa, MG: Universidade Federal de Minas Gerais, 1997. p.145-172.
PATTERSON, D.J.; PERRY, R.C.; KIRAKOFE, G.H. et al. Management considerations in heifer development and puberty. Journal of Animal Science, v.70, n.12, p.40184035, 1992.

RICE, L.E. Nutrition and the development of replacement heifers. Veterinarian Clinics of North America, v.7, n.1, p.27-42, 1991.

RYAN, W.J. Compensatory growth in cattle and sheep. Nutrition Abstracts and Reviews, v.60, n.9, p.653-664, 1990.

STATISTICAL ANALYSIS SYSTEM. SAS user's guide: Statistical, v.6.0. 3.ed. Cary, N.C.: 1990.

SAWYER, G.D.; BARKER, D.J.; MORRIS, J.B. Performance of young breeding cattle in commercial herds in the south-west of Western Australia I. liveweight, body condition, conception and fertility in first calf heifers. Australian Journal of Experimental Agricultural, v.31, n.4, p.443-454, 1991.

SEMMELMANN, C.E.N.; LOBATO, J.F.P.; ROCHA, M.G. Efeito de sistemas de alimentação no ganho de peso e desempenho reprodutivo de novilhas Nelore acasaladas aos 17/18 meses. Revista Brasileira de Zootecnia, v.30, n.3, p.835843, 2001.

TILLEY, J.M.A.; TERRY, R.A.A. Two stage technique for the "in vitro" digestion of forage crops. Journal of British Grassland Society, v.18, n.2, p.104-111, 1963.

WANYOIKE, M.M.; HOLMES, W. The effects of winter nutrition on the subsequent live-weight performance and intake of herbage by beef cattle. Journal of Agricultural Science, v.64, n.1, p.32-37, 1991. 